\title{
Protocolo para produção de material propagativo de batata em meio líquido ${ }^{(1)}$
}

\begin{abstract}
Jonny Everson Scherwinski Pereira ${ }^{(2)}$ e Gerson Renan de Luces Fortes ${ }^{(3)}$
Resumo - Os meios semi-sólidos são os mais utilizados em trabalhos de micropropagação, mas há indícios de que o estado físico dos meios de cultura influencia a multiplicação dos cultivos. O objetivo deste trabalho foi estabelecer um protocolo para a multiplicação de material propagativo de batata em meio de cultura líquido. Explantes de batata da cultivar Eliza, com uma gema axilar, foram cultivados em seis diferentes meios de cultura, com (semi-sólido) ou sem (líquido) a adição do solidificante ágar. Após 21 dias de cultivo, o meio de cultura que proporcionou os melhores resultados para crescimento e taxa de multiplicação teve sua composição modificada com o objetivo de melhorar a eficiência de multiplicação de cinco cultivares em meio líquido. Foi também avaliada a necessidade de agitação dos cultivos em meio líquido. Houve ganho na eficiência de multiplicação in vitro da batata, quando se utiliza meio de cultura líquido. Os melhores resultados são obtidos quando o material é cultivado em meio constituído pelos sais de MS na concentração plena, acrescido de ácido pantotênico $\left(5,0 \mathrm{mg} \mathrm{L}^{-1}\right)$, tiamina (1,0 mg L $\left.\mathrm{L}^{-1}\right)$ ácido giberélico $\left(0,25 \mathrm{mg} \mathrm{L}^{-1}\right)$ e sacarose $\left(20 \mathrm{~g} \mathrm{~L}^{-1}\right)$, sob agitação constante.
\end{abstract}

Termos para indexação: Solanum tuberosum, micropropagação, cultura in vitro, propagação vegetal.

Protocol for potato propagative material production in liquid medium

\begin{abstract}
Semi-solid media are more commonly used in studies of micropropagation, but the physical state of the culture media seems to influence the growth and multiplication rate of the cultivation. The objective of this work was to establish a protocol for in vitro multiplication of potato in liquid culture media. Potato explants, cultivar Eliza, with an axillary bud, were cultivated in six different culture media, with (semi-solid) or without (liquid) the addition of agar. After 21 days, the culture medium that provided the best results for growth and multiplication rate had the composition modified with the objective of improving the efficiency of in vitro multiplication of five cultivars in liquid medium. The need of agitation was also evaluated in liquid culture medium. There was high efficiency of the in vitro potato multiplication when it was cultivated in liquid medium. The MS salt medium in the full concentration, added by gibberellic acid $\left(0.25 \mathrm{mg} \mathrm{L}^{-1}\right)$, panthotenic acid $\left(5.0 \mathrm{mg} \mathrm{L}^{-1}\right)$, thiamine $\left(1.0 \mathrm{mg} \mathrm{L}^{-1}\right)$ and sucrose $\left(20 \mathrm{~g} \mathrm{~L}^{-1}\right)$, and under constant agitation, showed to be suitable for this purpose.
\end{abstract}

Index terms: Solanum tuberosum, micropropagation, in vitro culture, plant propagation.

\section{Introdução}

A técnica de cultivar tecidos de plantas in vitro vem sendo rotineiramente aplicada a inúmeras es-

\footnotetext{
(1)Aceito para publicação em 24 de junho de 2003.

(2) Embrapa-Centro de Pesquisa Agroflorestal do Acre, Caixa Postal 321, CEP 69908-970 Rio Branco, AC.

E-mail: jonny@cpafac.embrapa.br

${ }^{(3)}$ Embrapa-Centro Nacional de Pesquisa de Recursos Genéticos e Biotecnologia, Caixa Postal 02372, CEP 70770-900 Brasília, DF. E-mail: gerson@ cenargen.embrapa.br
}

pécies vegetais, pela possibilidade de manutenção da identidade genética dos indivíduos e obtenção de grande número de plantas sadias e de alta qualidade em pequeno espaço físico e em curto tempo, independentemente da época do ano. Por sua vez, o uso comercial da cultura de tecidos é ainda limitado, principalmente pelo elevado custo dos reagentes e equipamentos utilizados e pela relativa baixa eficiência no desenvolvimento e multiplicação que algumas espécies apresentam sob condições in vitro (Ziv, 1995; Kozay et al., 1997; Guerra et al., 1999). 
Em relação à cultura da batata (Solanum tuberosum L.), a micropropagação vem sendo amplamente utilizada, especialmente na produção de material propagativo com elevada qualidade fitossanitária, o que tem proporcionado benefícios diretos aos produtores, pelo conseqüente aumento nos níveis de produtividade da cultura (Assis, 1999).

$\mathrm{Na}$ etapa de multiplicação in vitro, a capacidade de os explantes sobreviverem, desenvolverem e se multiplicarem é consequiência de vários fatores, como o genético, o estado fisiológico e as concentrações endógenas de hormônios nos explantes e as condições ambientais de cultivo. Além disso, o uso de um meio de cultura apropriado para cada fase do cultivo é condição básica, devendo estes meios proporcionarem os nutrientes necessários ao metabolismo das células vegetais em cultivo para o crescimento e diferenciação dos tecidos (Kozay et al., 1997).

Vários ensaios tratam do assunto e muitos meios de cultura têm sido testados de modo a melhorar essas etapas. Contudo, os resultados são muitas vezes divergentes e nem sempre possíveis de serem reproduzidos. Isto se deve, principalmente, ao fato de a cultura de tecidos, como técnica de propagação vegetativa, necessitar ser adaptada às necessidades das espécies e cultivares, pois estas diferem geneticamente entre si, podendo apresentar resultados diferentes sob as mesmas condições de cultivo (Fortes \& Pereira, 2001).

Outro fator a ser considerado é o estado físico dos meios de cultura. A maioria dos trabalhos com batata in vitro baseia-se no uso de meios de cultura semi-sólidos (Caligari \& Powell, 1989; Ávila et al., 1994). Entretanto, a utilização de meios de cultura líquidos tem proporcionado igual ou até maior eficiência para diversas espécies vegetais, como o abacaxi (Escalona et al., 1999; Feuser et al., 2001), a banana (Alvard et al., 1993; Levin et al., 1997) e a cana-de-açúcar (Lorenzo et al., 1998). A facilidade na preparação e manipulação dos meios, a redução dos custos pela eliminação do ágar e a possibilidade de utilizar uma menor quantidade de meio de cultura, tem aumentado o interesse dos pesquisadores em trabalhar com este sistema. O material a ser multiplicado deve ser comprovadamente livre de contaminações, pois, nesse sistema, um único explante contaminado levará à contaminação de todos (Levin et al., 1997; Escalona et al., 1999).
O objetivo deste trabalho foi estabelecer um protocolo para a multiplicação de material propagativo de batata em meio de cultura líquido, testar esse protocolo para diferentes cultivares e estudar a influência da agitação no desenvolvimento in vitro dos cultivos.

\section{Material e Métodos}

O trabalho foi realizado no Laboratório de Cultura de Tecidos Vegetais da Embrapa-Centro de Pesquisa Agropecuária de Clima Temperado (CPACT), Pelotas, RS. Utilizou-se material propagativo de batata que se encontrava sob multiplicação em meio de cultura formado pelos sais e vitaminas de MS (Murashige \& Skoog, 1962); $100 \mathrm{mg} \mathrm{L}^{-1}$ de mio-inositol, $30 \mathrm{~g} \mathrm{~L}^{-1}$ de sacarose e $6 \mathrm{~g} \mathrm{~L}^{-1}$ de ágar, com pH ajustado para 5,8 $\pm 0,1$ antes da adição do ágar e autoclavagem. $\mathrm{O}$ material estava acondicionado em sala de crescimento a $25 \pm 2^{\circ} \mathrm{C}$, fotoperíodo de 16 horas e radiação de $35 \mu \mathrm{mol} \mathrm{m}{ }^{-2} \mathrm{~s}^{-1}$, fornecida por lâmpadas frias fluorescentes brancas.

Explantes de batata da cultivar Eliza, com 0,8 a 1,0 cm de comprimento e uma gema axilar, obtidos de material sob multiplicação in vitro, foram cultivados em seis diferentes meios de cultura, com (semi-sólido) ou sem (líquido) a adição do solidificante ágar $\left(6 \mathrm{~g} \mathrm{~L}^{-1}\right)$. Os meios de multiplicação foram assim constituídos: M1, formado pelo meio básico de MS; M2, formado pelos sais de MS, $30 \mathrm{~g} \mathrm{~L}^{-1}$ de sacarose, 2,0 $\mathrm{mg} \mathrm{L}^{-1}$ do ácido pantotênico, $0,4 \mathrm{mg} \mathrm{L}^{-1}$ de tiamina e os reguladores de crescimento ácido naftalenoacético (ANA) $\left(0,01 \mathrm{mg} \mathrm{L}^{-1}\right)$ e ácido giberélico $\left(\mathrm{AG}_{3}\right)\left(0,25 \mathrm{mg} \mathrm{L}^{-1}\right)$ (Chandra, 1991); M3, formado pelo meio de MS, reguladores ANA $\left(0,01 \mathrm{mg} \mathrm{L}^{-1}\right)$, cinetina $\left(1,0 \mathrm{mg} \mathrm{L}^{-1}\right)$ e $\mathrm{AG}_{3}\left(0,1 \mathrm{mg} \mathrm{L}^{-1}\right)$ (adaptado de Torres, 1987); M4, formado pelos sais do meio MS, $30 \mathrm{~g} \mathrm{~L}^{-1}$ de sacarose e 2,0 $\mathrm{mg} \mathrm{L}^{-1}$ do ácido pantotênico (Tovar et al., 1985); M5, formado pelo meio MS, $1,0 \mathrm{mg} \mathrm{L}^{-1}$ de 2-cloropiridilfeniluréia (CPPU) (Akita \& Ohta, 1998); M6, constituído pelo meio básico de MS, 2,0 $\mathrm{mg} \mathrm{L}^{-1}$ de cinetina, 6,0 $\mathrm{mg} \mathrm{L}^{-1}$ de ancimidol e $100 \mathrm{mg} \mathrm{L}^{-1}$ de sulfato de adenina (Osmotek Ltd., 2000).

Adotou-se esquema fatorial $2 \times 6$, com duas consistências para o meio de multiplicação (semi-sólida e líquida) e seis tipos de meio de cultura (M1, M2, M3, M4, M5 e M6). O delineamento experimental foi inteiramente ao acaso, com cinco repetições por tratamento, sendo cada parcela formada por dez explantes.

Após a avaliação dos dados, o meio de cultura que propiciou os melhores resultados em relação às variáveis estudadas foi modificado com o objetivo de melhorar a eficiência de multiplicação de batata no sistema líquido. 
Para tanto, diferentes concentrações dos constituintes ANA $\left(0,0,01,0,02,0,03,0,04\right.$ e $\left.0,05 \mathrm{mg} \mathrm{L}^{-1}\right), \mathrm{AG}_{3}(0,0,125$, $0,25,0,375,0,5,0,625$ e $\left.0,75 \mathrm{mg} \mathrm{L}^{-1}\right)$, ácido pantotênico $\left(0,2,5,5,0,7,5,10,0,12,5\right.$ e $\left.15 \mathrm{mg} \mathrm{L}^{-1}\right)$, tiamina $(0,1,0$, 2, $0,3,0,4,0,5,0$ e $\left.6,0 \mathrm{mg} \mathrm{L}^{-1}\right)$, sacarose (20,30 e $\left.40 \mathrm{~g} \mathrm{~L}^{-1}\right)$ e sais de MS $\left(1 / 2,3 / 4\right.$, pleno e $\left.1 \frac{1 / 4}{4}\right)$ foram testadas, somente em meio líquido. $\mathrm{O}$ experimento em que se avaliou a influência das concentrações de sacarose e dos sais de MS no meio de multiplicação seguiu um esquema fatorial $3 \times 4$, com três concentrações de sacarose $\left(20,30\right.$ e $\left.40 \mathrm{~g} \mathrm{~L}^{-1}\right)$ e quatro do meio de MS $\left(1 / 2,3 / 4\right.$, pleno e $\left.1 \frac{1 / 4}{4}\right)$. Nos demais, os componentes foram avaliados em ensaios individuais.

Utilizaram-se explantes de batata com 0,5 a $1,0 \mathrm{~cm}$ de comprimento e uma gema axilar, obtidos de material sob multiplicação in vitro da cultivar Eliza. O delineamento experimental foi o de blocos casualizados, com cinco repetições por tratamento, sendo cada parcela constituída de dez explantes.

Para verificar o possível ganho em eficiência do novo meio de cultura, avaliou-se o comportamento de cinco cultivares de batata sob condições de multiplicação em meio de cultura líquido. Explantes das cultivares Baronesa, Cristal, Eliza, Macaca e Pérola, obtidos de material sob multiplicação in vitro, com tamanho aproximado de 0,8 a $1,0 \mathrm{~cm}$ e uma gema axilar, foram cultivados no meio de cultura melhorado, denominado M2M (sais de MS na concentração plena, $0,25 \mathrm{mg} \mathrm{L}^{-1} \mathrm{de} \mathrm{AG}_{3}, 5,0 \mathrm{mg} \mathrm{L}^{-1}$ do ácido pantotênico, $1,0 \mathrm{mg} \mathrm{L}^{-1}$ de tiamina e $20 \mathrm{~g} \mathrm{~L}^{-1}$ do sacarose), com base nos resultados obtidos nos experimentos anteriores. A este meio, comparou-se ainda o meio básico de MS, rotineiramente utilizado em trabalhos de multiplicação no Laboratório de Cultura de Tecidos da Embrapa-CPACT, e o meio M2, o qual deu origem aos trabalhos de ajuste do novo meio de cultura.

Adotou-se um esquema fatorial $3 \times 5$, com três diferentes meios de cultura e cinco cultivares. $\mathrm{O}$ delineamento experimental foi o de blocos casualizados, com quatro repetições por tratamento, sendo cada parcela formada por dez explantes.

No ensaio de agitação dos cultivos em meio líquido, explantes de batata das cultivares Baronesa, Eliza e Pérola, obtidos de material sob multiplicação in vitro com 0,8 a $1,0 \mathrm{~cm}$ de comprimento, foram inoculados em erlenmeyers de $250 \mathrm{~mL}$ com $15 \mathrm{~mL}$ de meio de cultura líquido M2M e colocados sob diferentes períodos de agitação: 0 (cultura estacionária), 6, 12, 18 e 24 horas (80 a $90 \mathrm{rpm}$ ). Adotou-se esquema fatorial $3 \times 5$, com três cultivares e cinco períodos de agitação. $\mathrm{O}$ delineamento experimental foi o de blocos casualizados, com quatro repetições por tratamento e cada parcela formada por dez explantes.
Em todos os ensaios de multiplicação, os dados foram coletados após 21 dias de cultivo dos explantes. As variáveis avaliadas foram: altura de brotação (porção compreendida entre a região do colo e a inserção da última folha) e taxa de multiplicação do material vegetal (contagem do número de gemas formadas no final do período de cultivo, excluindo-se a apical). No experimento em que se estudou a influência de diferentes meios de cultura, também foram avaliados a massa de matéria fresca e seca das plântulas e o conteúdo de água nos tecidos. A determinação da massa das plantas foi feita após secagem em estufa a $65^{\circ} \mathrm{C}$ até peso constante. A massa das plantas foi determinada em balança digital analítica e o conteúdo de água nos tecidos, pela diferença entre as massas da matéria fresca e seca das plantas.

Os dados foram submetidos à análise de variância e de regressão, e as médias comparadas pelo teste de Duncan a $5 \%$ de probabilidade. Os dados expressos em porcentagem $(\mathrm{x})$ foram transformados em arco seno $(\mathrm{x} / 100)^{0,5}$. Os dados referentes à taxa de multiplicação $(\mathrm{x})$ foram transformados em $(x+0,9)^{0,5}$.

Utilizaram-se frascos erlenmeyers de $250 \mathrm{~mL}$ com $40 \mathrm{~mL}$ de meio de cultura nos experimentos cujos explantes se desenvolveram em meio sólido, e com $15 \mathrm{~mL}$ quando os explantes se desenvolveram em meio líquido.

Com exceção do experimento no qual testaram-se diferentes períodos de agitação dos cultivos, os demais ensaios de multiplicação em meio líquido foram realizados sob agitação contínua, em mesa agitadora do tipo orbital (80 a $90 \mathrm{rpm}$ ).

Os cultivos foram mantidos em sala de crescimento a $25 \pm 2{ }^{\circ} \mathrm{C}$, fotoperíodo de 16 horas e radiação luminosa de $35 \mu \mathrm{mol} \mathrm{m}{ }^{-2} \mathrm{~s}^{-1}$, fornecida por lâmpadas fluorescentes brancas.

\section{Resultados e Discussão}

A utilização de meios de cultura de consistência líquida proporcionou aumento significativo na taxa de multiplicação, especialmente quando o material vegetal foi cultivado no meio de cultura M2 (Tabela 1). É provável que esse resultado seja por causa do aumento da disponibilidade de água e nutrientes proporcionado por esse meio de cultivo (Levin et al., 1997; Chen \& Ziv, 2001), no qual não existe resistência física para a difusão dos nutrientes, quando comparado aos meios de cultura de consistência semi-sólida. Além disso, o maior contato dos explantes e raízes com o meio faz com que a taxa de assimilação de nutrientes pelo material vegetal em cultivo seja 
favorecida no meio líquido (Ziv, 1995). Com exceção do meio M5, que apresentou brotações significativamente maiores em meio semi-sólido, os meios de cultura testados não diferiram quanto a altura das brotações e taxa de multiplicação em razão da consistência, o que permite deduzir que o meio de cultura M2 foi o que melhor se adaptou a esse processo de cultivo.

Embora no presente trabalho não se tenha observado vitrificação dos explantes, a utilização de meios líquidos ou com baixas concentrações do solidificante ágar pode levar à vitrificação dos cultivos, influenciando negativamente a morfogênese in vitro. Por isso, mesmo apresentando vantagens em relação ao meio semi-sólido, o uso de meios líquidos pode não ser adequado para determinadas espécies, principalmente as lenhosas, nas quais é comum o surgimento de brotações com essa característica (Chen \& Ziv, 2001).

Além da altura e taxa de multiplicação, a determinação do acúmulo da massa constitui-se excelente indicador do crescimento vegetal. Com exceção do meio de cultura M5, a massa da matéria seca das plantas foi significativamente maior quando cultivadas em meio líquido (Tabela 1). Além disso, na maioria dos meios de cultura, explantes desenvolvidos em meio líquido não mostraram diferenças no conteúdo de água dos tecidos quando comparados aos resultados obtidos em meio semi-sólido, indicando que os efeitos da consistência do meio sobre o acúmulo de matéria seca das plantas não estão relacionados somente com a maior disponibilidade de água, como relatado por Debergh (1983), mas também com o melhor desempenho assimilatório das plantas proporcionado pelo meio líquido, durante o período de cultivo do material vegetal (Ziv, 1995).

Ainda que o meio M2 tenha proporcionado os melhores resultados de taxa de multiplicação e altura de brotações, quanto a matéria fresca e seca das plantas, os meios M3 e M4 líquidos foram os que proporcionaram os maiores valores, possivelmente por causa da intensa formação de calo nos explantes cultivados. Não houve diferença significativa entre os meios de cultura na consistência semi-sólida quanto a essas variáveis (Tabela 1).

Embora as auxinas sejam amplamente utilizadas na cultura de tecidos para a indução do enraizamento,
Tabela 1. Influência de diferentes meios de cultura sobre a altura das brotações, taxa de multiplicação, massa da matéria fresca e seca das plantas e conteúdo de água nos tecidos de batata, cultivar Eliza, após 21 dias de cultivo ${ }^{(1)}$.

\begin{tabular}{|c|c|c|}
\hline \multirow{2}{*}{$\begin{array}{l}\text { Meio de } \\
\text { cultura }^{(2)}\end{array}$} & \multicolumn{2}{|c|}{ Consistência do meio de cultura } \\
\hline & Semi-sólido & Líquido \\
\hline & \multicolumn{2}{|c|}{ Altura das brotações $(\mathrm{cm})$} \\
\hline M1 & $3,82 \mathrm{bA}$ & $3,89 \mathrm{bA}$ \\
\hline M2 & $4,69 \mathrm{aA}$ & $4,73 \mathrm{aA}$ \\
\hline M3 & $3,31 \mathrm{bA}$ & $3,14 \mathrm{cA}$ \\
\hline M4 & $3,22 \mathrm{bA}$ & $3,57 \mathrm{bcA}$ \\
\hline M5 & $2,02 \mathrm{cA}$ & $0,61 \mathrm{~dB}$ \\
\hline \multirow[t]{2}{*}{ M6 } & $1,55 \mathrm{cA}$ & $1,18 \mathrm{dA}$ \\
\hline & \multicolumn{2}{|c|}{ Taxa de multiplicação ${ }^{(3)}$} \\
\hline M1 & $6,37 \mathrm{abA}$ & $6,75 \mathrm{bA}$ \\
\hline M2 & $6,83 \mathrm{aB}$ & $8,01 \mathrm{aA}$ \\
\hline M3 & $6,21 \mathrm{abA}$ & $6,99 \mathrm{bA}$ \\
\hline M4 & $6,17 \mathrm{abA}$ & $6,51 \mathrm{bA}$ \\
\hline M5 & $5,04 \mathrm{cA}$ & $4,46 \mathrm{dA}$ \\
\hline \multirow[t]{2}{*}{ M6 } & $5,34 \mathrm{bcA}$ & $5,39 \mathrm{cA}$ \\
\hline & \multicolumn{2}{|c|}{ Massa da matéria fresca das plantas $(\mathrm{g})$} \\
\hline M1 & $0,37 \mathrm{aB}$ & $0,87 \mathrm{cA}$ \\
\hline M2 & $0,50 \mathrm{aB}$ & $1,22 \mathrm{bA}$ \\
\hline M3 & $0,32 \mathrm{aB}$ & $1,32 \mathrm{abA}$ \\
\hline M4 & $0,26 \mathrm{aB}$ & $1,50 \mathrm{aA}$ \\
\hline M5 & $0,22 \mathrm{aB}$ & $0,60 \mathrm{dA}$ \\
\hline M6 & $0,38 \mathrm{aB}$ & $0,87 \mathrm{cA}$ \\
\hline & \multicolumn{2}{|c|}{ Massa da matéria seca das plantas (g) } \\
\hline M1 & $0,019 \mathrm{aB}$ & $0,076 \mathrm{abA}$ \\
\hline M2 & $0,042 \mathrm{aB}$ & $0,077 \mathrm{abA}$ \\
\hline M3 & $0,038 \mathrm{aB}$ & $0,094 \mathrm{aA}$ \\
\hline M4 & $0,026 \mathrm{aB}$ & $0,093 \mathrm{aA}$ \\
\hline M5 & $0,039 \mathrm{aA}$ & $0,057 \mathrm{bA}$ \\
\hline \multirow[t]{2}{*}{ M6 } & $0,035 \mathrm{aB}$ & $0,070 \mathrm{abA}$ \\
\hline & \multicolumn{2}{|c|}{ Conteúdo de água (\%) } \\
\hline M1 & $94,9 \mathrm{aA}$ & $91,3 \mathrm{aA}$ \\
\hline M2 & $91,6 \mathrm{abA}$ & $93,7 \mathrm{aA}$ \\
\hline M3 & $88,1 \mathrm{bB}$ & $92,9 \mathrm{aA}$ \\
\hline M4 & $90,0 \mathrm{bA}$ & $93,8 \mathrm{aA}$ \\
\hline M5 & $82,3 \mathrm{cB}$ & $90,5 \mathrm{aA}$ \\
\hline M6 & $90,8 \mathrm{bA}$ & $91,9 \mathrm{aA}$ \\
\hline
\end{tabular}

(1)Médias seguidas por letras distintas, minúsculas na vertical e maiúsculas na horizontal, diferem entre si pelo teste de Duncan, a 5\% de probabilidade. ${ }^{(2)} \mathrm{M} 1$ : meio básico de MS; M2: sais de MS $+30 \mathrm{~g} \mathrm{~L}^{-1}$ de sacarose + $2,0 \mathrm{mg} \mathrm{L}^{-1}$ do ácido pantotênico $+0,4 \mathrm{mg} \mathrm{L}^{-1}$ de tiamina $+0,01 \mathrm{mg} \mathrm{L}^{-1}$ de ácido naftalenoacético (ANA) + 0,25 mg L-1 de ácido giberélico $\left(\mathrm{AG}_{3}\right)$; M3: meio de $\mathrm{MS}+0,01 \mathrm{mg} \mathrm{L}^{-1}$ de ANA $+1,0 \mathrm{mg} \mathrm{L}^{-1}$ de cinetina + $0,1 \mathrm{mg} \mathrm{L}^{-1}$ de $\mathrm{AG}_{3} ; \mathrm{M} 4$ : sais de $\mathrm{MS}+30 \mathrm{~g} \mathrm{~L}^{-1}$ de sacarose $+2,0 \mathrm{mg} \mathrm{L}^{-1}$ do ácido pantotênico; $\mathrm{M} 5$ : meio $\mathrm{MS}+1,0 \mathrm{mg} \mathrm{L}^{-1}$ de 2-cloropiridilfeniluréia (CPPU); M6: meio básico de MS + 2,0 $\mathrm{mg} \mathrm{L}^{-1}$ de cinetina $+6,0 \mathrm{mg} \mathrm{L}^{-1}$ de ancimidol $+100 \mathrm{mg} \mathrm{L}^{-1}$ de sulfato de adenina. ${ }^{(3)}$ Número de gemas formadas no final do período de cultivo, excluindo-se a apical. 
em baixas concentrações, elas também promovem a divisão celular e a elongação dos tecidos (Davis, 1987). Entretanto, a presença de ANA no meio de cultura não proporcionou melhora significativa nos resultados (Tabela 2). Além disso, observou-se que as brotações mostraram sensibilidade na formação de calo a partir da concentração de $0,03 \mathrm{mg} \mathrm{L}^{-1}$, o que é indesejável, já que pode resultar em variação genética no material (Skirvin et al., 1993).

A presença de $A_{3}$ exerceu influência determinante sobre o crescimento e multiplicação do material. Embora a concentração mais baixa deste regulador já tivesse proporcionado melhoria na resposta do cultivo em meio líquido, especialmente quanto a taxa de multiplicação, os melhores resultados foram obtidos a partir da concentração de $0,25 \mathrm{mg} \mathrm{L}^{-1}$. Deste ponto em diante, não mais se observaram acréscimos significativos em relação a essa variável.

Segundo Grattapaglia \& Machado (1998), a manipulação de vitaminas no meio de cultura geralmente não resulta em expressivas alterações na multiplicação. Entretanto, a presença como constituintes do meio de cultura é importante por desempenharem funções catalíticas nos sistemas enzimáticos, influ- enciando diretamente o crescimento e desenvolvimento dos cultivos (Krikorian, 1991). No presente trabalho, o aumento da concentração de ambas as vitaminas levou a uma melhora significativa da taxa de multiplicação do material vegetal (Tabela 2). Em relação ao ácido pantotênico, os melhores resultados foram observados na concentração de $5,0 \mathrm{mg} \mathrm{L}^{-1} \mathrm{e}$, quanto a tiamina, a partir da concentração de $1,0 \mathrm{mg} \mathrm{L}^{-1}$. Concentrações inferiores de ambas as vitaminas levaram a um comportamento linear ascendente das variáveis respostas, sendo necessário, por isso, o estudo de concentrações mais elevadas. Verificou-se que após terminada esta etapa de ajustes a taxa média de multiplicação do material vegetal chegou a 8,6:1, com as plantas atingindo $6,4 \mathrm{~cm}$, aproximadamente, ao final de 21 dias de cultivo.

Se em algumas espécies diluições nas formulações básicas do meio de cultura provocam melhora nos resultados, neste trabalho houve comportamento nitidamente ascendente da altura de brotações e taxa de multiplicação com o aumento nas concentrações de sais de MS presentes no meio de cultura, principalmente quando este foi suplementado com sacarose a 20 e $30 \mathrm{~g} \mathrm{~L}^{-1}$ (Figura 1). Em meio de cultura com $40 \mathrm{~g} \mathrm{~L}^{-1}$ de sacarose, este comportamen-

Tabela 2. Influência de diferentes concentrações de ácido naftalenoacético (ANA), ácido giberélico $\left(\mathrm{AG}_{3}\right)$, ácido pantotênico e tiamina sobre a altura de brotações e taxa de multiplicação em batata, cultivar Eliza, em meio de multiplicação de consistência líquida, após 21 dias de cultivo(1).

\begin{tabular}{|c|c|c|c|c|c|c|c|}
\hline \multirow[t]{2}{*}{ Variável } & \multicolumn{7}{|c|}{ ANA $\left(\mathrm{mg} \mathrm{L}^{-1}\right)$} \\
\hline & 0,00 & 0,01 & 0,02 & 0,03 & 0,04 & 0,05 & \\
\hline Altura de brotações $(\mathrm{cm})$ & $5,38 \mathrm{a}$ & $5,27 \mathrm{a}$ & $5,68 \mathrm{a}$ & $5,82 \mathrm{a}$ & $5,17 \mathrm{a}$ & $5,20 \mathrm{a}$ & \\
\hline \multirow{3}{*}{ Taxa de multiplicação ${ }^{(2)}$} & $6,73 a$ & $6,62 \mathrm{a}$ & $6,36 \mathrm{a}$ & $6,67 \mathrm{a}$ & $6,45 \mathrm{a}$ & $6,88 \mathrm{a}$ & \\
\hline & \multicolumn{7}{|c|}{$\mathrm{AG}_{3}\left(\mathrm{mg} \mathrm{L}^{-1}\right)$} \\
\hline & 0,0 & 0,125 & 0,250 & 0,375 & 0,500 & 0,625 & 0,750 \\
\hline Altura de brotações $(\mathrm{cm})$ & $3,44 b$ & $6,07 \mathrm{a}$ & $5,91 \mathrm{a}$ & $5,63 \mathrm{a}$ & $6,26 a$ & $6,38 \mathrm{a}$ & $6,26 a$ \\
\hline \multirow[t]{3}{*}{ Taxa de multiplicação ${ }^{(2)}$} & $5,30 \mathrm{c}$ & $6,67 \mathrm{~b}$ & $7,60 \mathrm{a}$ & $7,03 \mathrm{ab}$ & $7,50 \mathrm{a}$ & $7,78 \mathrm{a}$ & $7,15 \mathrm{ab}$ \\
\hline & \multicolumn{7}{|c|}{ Ácido pantotênico $\left(\mathrm{mg} \mathrm{L}^{-1}\right)$} \\
\hline & 0,0 & 2,5 & 5,0 & 7,5 & 10,0 & 12,5 & 15,0 \\
\hline Altura de brotações $(\mathrm{cm})$ & $6,10 \mathrm{a}$ & $6,00 \mathrm{a}$ & $6,25 \mathrm{a}$ & $6,37 a$ & $6,36 a$ & $5,96 \mathrm{a}$ & $6,02 a$ \\
\hline \multirow[t]{3}{*}{ Taxa de multiplicação ${ }^{(2)}$} & $7,52 \mathrm{~b}$ & $7,56 \mathrm{~b}$ & $8,47 \mathrm{a}$ & $8,17 \mathrm{a}$ & $8,04 \mathrm{ab}$ & $8,07 \mathrm{ab}$ & $7,96 \mathrm{ab}$ \\
\hline & \multicolumn{7}{|c|}{ Tiamina $\left(\mathrm{mg} \mathrm{L}^{-1}\right)$} \\
\hline & 0,0 & 1,0 & 2,0 & 3,0 & 4,0 & 5,0 & 6,0 \\
\hline Altura de brotações $(\mathrm{cm})$ & $6,25 \mathrm{a}$ & $5,83 \mathrm{a}$ & $6,38 \mathrm{a}$ & $6,16 a$ & $6,34 a$ & $6,24 a$ & $6,36 a$ \\
\hline Taxa de multiplicação ${ }^{(2)}$ & $7,45 \mathrm{~b}$ & $8,59 a$ & $8,53 a$ & $8,60 \mathrm{a}$ & $8,28 \mathrm{ab}$ & $8,54 \mathrm{a}$ & $8,13 \mathrm{ab}$ \\
\hline
\end{tabular}

${ }^{(1)}$ Médias seguidas da mesma letra, na linha, não diferem entre si pelo teste de Duncan, a $5 \%$ de probabilidade. (2)Número de gemas formadas no final do período de cultivo, excluindo-se a apical. 
to ascendente também foi observado, mas até a concentração plena de MS; a partir daí houve decréscimo nos valores das variáveis estudadas. Quando se avaliou a melhor concentração de sacarose utilizada, observou-se que, de maneira geral, a concentração de $20 \mathrm{~g} \mathrm{~L}^{-1}$ foi a que proporcionou os melhores resultados em ambas variáveis estudadas. Por isso, convencionou-se utilizar, nos experimentos seguintes de ajuste do protocolo para multiplicação de batata em meio líquido, meio de cultura com $20 \mathrm{~g} \mathrm{~L}^{-1}$ de sacarose e na concentração plena dos sais do meio MS.

Para verificar a eficiência de multiplicação em meio líquido a partir do meio de cultura previamente ajustado, cinco cultivares de batata foram comparadas quanto ao comportamento no meio de cultura M2M, no meio básico que lhe deu origem (M2) e no meio de cultura MS, rotineiramente utilizado para a multiplicação da batata. Tanto em termos de altura quanto de taxa de multiplicação do material vegetal, não foi verificada interação significativa entre cultivares x meio de cultura. Entre os genótipos testados, a cultivar Macaca foi a que apresentou os melhores resultados em altura de brotações, independentemente do meio de cultura onde foram cultivadas (Tabela 3). A cultivar Cristal teve o menor crescimento em meio líquido, com brotações, em média, de 3,62 cm. A taxa de multiplicação foi significativamente maior na cultivar Macaca (8,62:1) e menor na Cristal $(6,36: 1)$. As outras cultivares testadas não apresentaram diferenças significativas entre si quanto a essa variável (Tabela 3 ).

Quando se avaliou a altura de brotações em razão do tipo de meio de cultura utilizado, verificou-se que, independentemente dos genótipos testados, os melhores resultados foram obtidos quando o material foi cultivado nos meios M2M e M2. Quanto à taxa de multiplicação, resultados superiores foram obtidos quando os genótipos se desenvolveram no meio M2M (Tabela 3).

Tais resultados confirmam a hipótese de que o ajuste do meio de cultura proporciona melhoria, principalmente na taxa de multiplicação do material vegetal. França (2000), trabalhando com meio de cultura de consistência semi-sólida com as cultivares Baronesa, Macaca e Cristal, obteve taxas de multiplicação de 5,9, 5,4 e 5,1, respectivamente, portanto, inferiores às obtidas no presente trabalho.

Normalmente, cultivos em meio líquido requerem um suporte ou agitação para fornecer o oxigê-
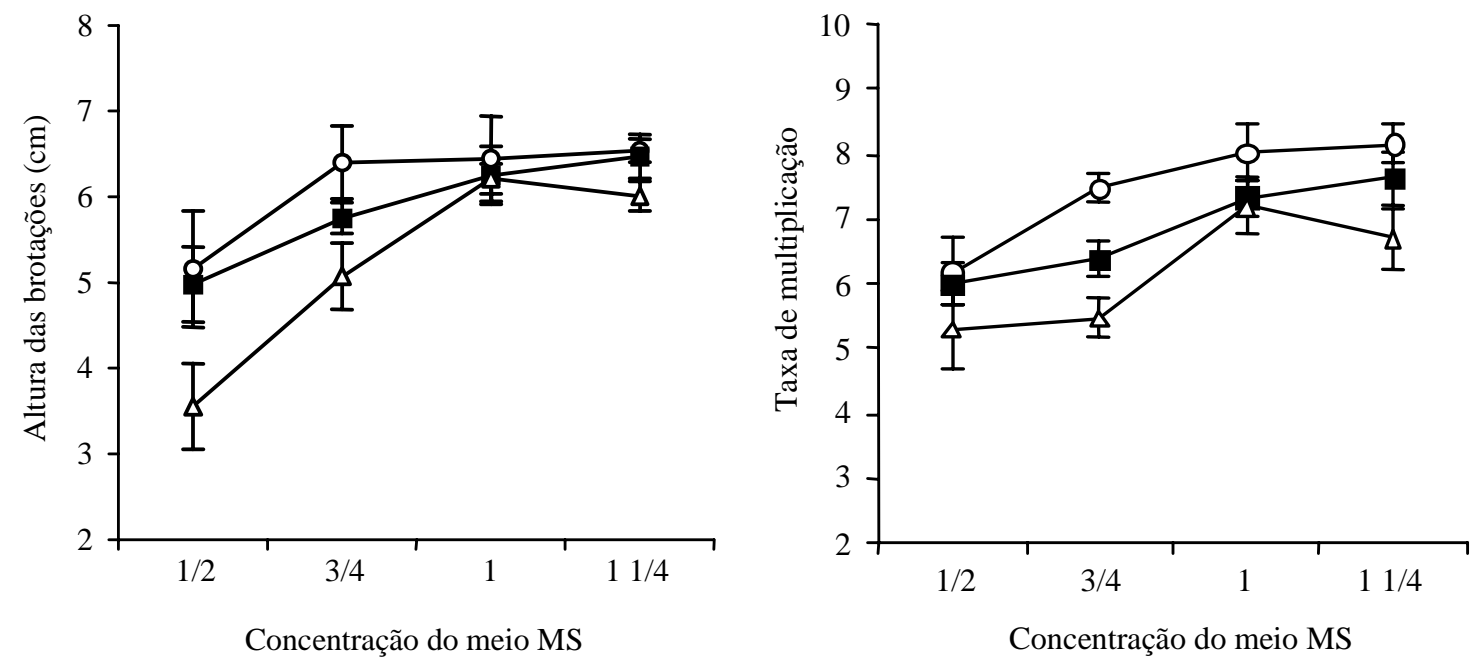

Figura 1. Influência de diferentes concentrações do meio de cultura MS e de $20(O), 30(\mathbf{\square})$ e $40 \mathrm{~g} \mathrm{~L}^{-1}(\triangle)$ de sacarose sobre a altura das brotações e a taxa de multiplicação (número de gemas formadas no final do período de cultivo, excluindo-se a apical) em batata, cultivar Eliza, em meio de cultura líquido, após 21 dias de cultivo. Barra vertical em cada ponto representa o desvio-padrão da média. 
nio necessário para a respiração do explante (Alvard et al., 1993; Grattapaglia \& Machado, 1998). Em batata, a necessidade de agitação desses cultivos foi estudada avaliando-se o comportamento das cultivares Baronesa, Eliza e Pérola. O modelo linear foi o mais adequado para explicar o crescimento e a taxa de multiplicação das cultivares nos diferentes períodos de agitação do meio líquido (Figura 2). Embora o período de 24 horas tenha proporcionado os melhores resultados, observou-se que no sistema sem agitação também houve bom crescimento e multiplicação do material vegetal. Brotações das cultivares Baronesa, Eliza e Pérola mantidas em meio líquido sem agitação apresentaram altura média de 5,5, 5,3 e 5,2 cm e taxa de multiplicação de 6,4, 5,4 e 5,5 , respectivamente. Quando em meio com 24 horas de agitação, essas cultivares apresentaram brotações com altura de 7,0, 6,5 e 6,3 cm e taxa de multiplicação de 8,5, 7,5 e 8,0, respectivamente. Portanto, mesmo que os resultados tenham sido significativamente superiores, novos trabalhos deverão ser realizados para comprovar a necessidade de manter os explantes sob contínua agitação. É possível que a agitação do meio de cultura deva ser feita especialmente na pri-

Tabela 3. Altura de brotações e taxa de multiplicação de batata em meio de cultura de consistência líquida em razão da cultivar e do meio de cultura, após 21 dias de culti$\mathrm{vo}^{(1)}$.

\begin{tabular}{lcc}
\hline Cultivar & $\begin{array}{c}\text { Altura das } \\
\text { brotações }(\mathrm{cm})\end{array}$ & $\begin{array}{c}\text { Taxa de } \\
\text { multiplicação }\end{array}$ \\
\hline Macaca & $6,35 \mathrm{a}$ & $8,62 \mathrm{a}$ \\
Pérola & $5,89 \mathrm{~b}$ & $7,33 \mathrm{~b}$ \\
Eliza & $5,6 \mathrm{bc}$ & $7,73 \mathrm{~b}$ \\
Baronesa & $5,51 \mathrm{c}$ & $7,82 \mathrm{~b}$ \\
Cristal & $3,62 \mathrm{~d}$ & $6,36 \mathrm{c}$ \\
\hline Meio de cultura ${ }^{(3)}$ & & \\
\hline M2M & $5,85 \mathrm{a}$ & $8,59 \mathrm{a}$ \\
M2 & $5,58 \mathrm{a}$ & $7,41 \mathrm{~b}$ \\
MS & $4,75 \mathrm{~b}$ & $6,72 \mathrm{c}$ \\
\hline
\end{tabular}

(1)Médias seguidas da mesma letra, na coluna, não diferem entre si pelo teste de Duncan, a 5\% de probabilidade. ${ }^{(2)}$ Número de gemas formadas no final do período de cultivo, excluindo-se a apical. ${ }^{\left({ }^{3}\right)} \mathrm{M} 2 \mathrm{M}$ : sais de MS + $20 \mathrm{~g} \mathrm{~L}^{-1}$ de sacarose + 5,0 $\mathrm{mg} \mathrm{L}^{-1}$ do ácido pantotênico + 1,0 $\mathrm{mg} \mathrm{L}^{-1}$ de tiamina $+0,25 \mathrm{mg} \mathrm{L}^{-1}$ de ácido giberélico $\left(\mathrm{AG}_{3}\right)$; $\mathrm{M} 2$ : sais de $\mathrm{MS}+$ $30 \mathrm{~g} \mathrm{~L}^{-1}$ de sacarose $+2,0 \mathrm{mg} \mathrm{L}^{-1}$ do ácido pantotênico $+0,4 \mathrm{mg} \mathrm{L}^{-1} \mathrm{de}$ tiamina $+0,01 \mathrm{mg} \mathrm{L}^{-1}$ de ácido naftalenoacético (ANA) + 0,25 mg L-1 de ácido giberélico $\left(\mathrm{AG}_{3}\right)$; MS: meio básico de MS meira semana de cultivo, uma vez que é o período em que os explantes permanecem totalmente imersos no meio de cultura, o que pode influenciar o crescimento inicial.

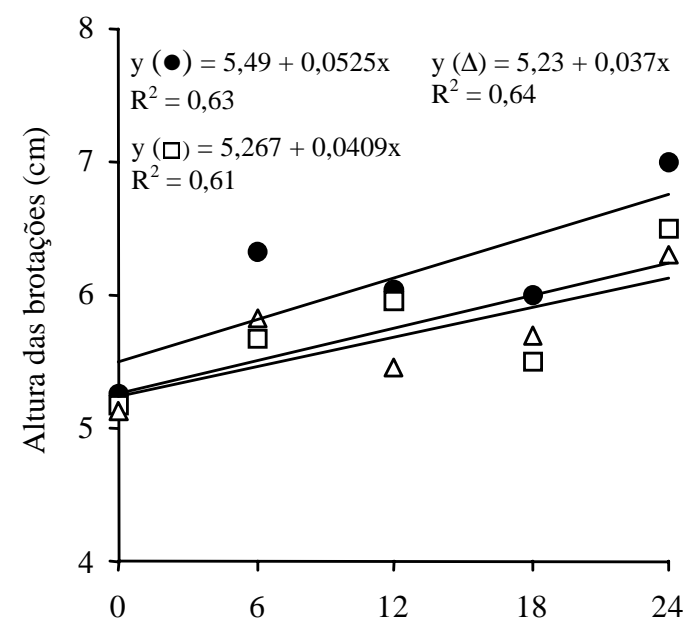

Tempo de agitação (horas)

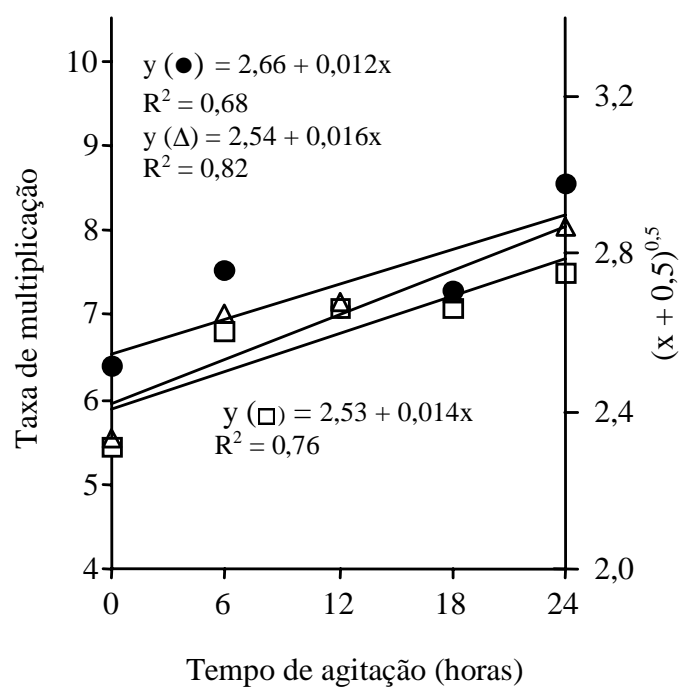

Figura 2. Altura de brotações e taxa de multiplicação (número de gemas formadas no final do período de cultivo, excluindo-se a apical) nas cultivares de batata Baronesa $(\bullet)$, Eliza $(\triangle)$ e Pérola $(\square)$ sob cultivo em meio líquido em razão do tempo de agitação, após 21 dias de cultivo. 


\section{Conclusões}

1. A cultura da batata apresenta excelente adaptabilidade para cultivo em meio de cultura líquido.

2. Há ganho em eficiência na multiplicação de material propagativo de batata sob condições in vitro quando se utiliza meio de cultura líquido.

3. O meio formado por sais de MS na concentração plena, suplementado com $\mathrm{AG}_{3}\left(0,25 \mathrm{mg} \mathrm{L}^{-1}\right)$, ácido pantotênico $\left(5,0 \mathrm{mg} \mathrm{L}^{-1}\right)$, tiamina $\left(1,0 \mathrm{mg} \mathrm{L}^{-1}\right)$ e sacarose $\left(20 \mathrm{~g} \mathrm{~L}^{-1}\right)$ é adequado para multiplicações de material propagativo.

4. Os melhores resultados para multiplicação e crescimento de material de batata em meio líquido são obtidos com agitação contínua.

\section{Referências}

AKITA, M.; OHTA, Y. A simple method for mass propagation of potato (Solanum tuberosum L.) using a bioreactor without forced aeration. Plant Cell Reports, New York, v. 18, p. 284-287, 1998.

ALVARD, D.; COTE, F.; TEISSON, C. Comparison of methods of liquid medium cultures for banana micropropagation: effect of temporary immersion of explants. Plant Cell, Tissue and Organ Culture, Dordrecht, v. 32, p. 55-60, 1993.

ASSIS, M. Novas tecnologias na propagação de batata. Informe Agropecuário, Belo Horizonte, v. 20, n. 197, p. 30-33, 1999.

ÁVILA, A.; PEREYRA, L. S. M.; COLLINO, D. J.; ARGÜELLO, J. A. Effects of nitrogen source on growth and morphogenesis of three micropropagated potato cultivars. Potato Research, Wageningen, v. 37, p. 161-168, 1994

CALIGARI, P. D. S.; POWELL, W. Variability in response of potato cultivars to micropropagation - I: in vitro performance. Annals of Applied Biology, London, v. 115, p. 115-121, 1989.

CHANDRA, R. Problems in in vitro conservation of potato germplasm at CPRI, Shimla. Journal of Indian Potato Association, New Deli, v. 18, n. 3/4, p. 162-166, 1991.

CHEN, J.; ZIV, M. The effect of ancymidol on hyperhydricity, regeneration, starch and antioxidant enzymatic activities in liquid-culture Narcissus. Plant Cell Reports, New York, v. 20, p. 22-27, 2001.

Pesq. agropec. bras., Brasília, v. 38, n. 9, p. 1035-1043, set. 2003
DAVIS, P. J. The plant hormones: their nature, occurrence, and functions. In: PLANT hormones and their role in plant growth and development. Dordrecht: Kluver Academic, 1987. p. 1-11.

DEBERGH, P. C. Effects of agar brand and concentration on the tissue culture medium. Physiologia Plantarum, Copenhagen, v. 59, p. 270-276, 1983.

ESCALONA, M.; LORENZO, J. C.; GONZÁLEZ, B.; DAQUINTA, M.; GONZÁLEZ, J. L.; DESJARDINS, Y.; BORROTO, C. G. Pineapple (Ananas comosus L. Merr) micropropagation in temporary immersion systems. Plant Cell Reports, New York, v. 18, p. 743-748, 1999.

FEUSER, S.; NODARI, R. O.; GUERRA, M. P. Eficiência comparativa dos sistemas de cultura estacionária e imersão temporária para a micropropagação do abacaxi. Revista Brasileira de Fruticultura, Jaboticabal, v. 23, n. 1, p. 6-10, 2001.

FORTES, G. R. L.; PEREIRA, J. E. S. Estabelecimento in vitro da ameixeira cv. América. Revista Brasileira de Fruticultura, Jaboticabal, v. 23, n. 1, p. 183-185, 2001.

FRANÇA, R. B. Aspectos bioquímicos de cultivares de batata (Solanum tuberosum L.) multiplicadas in vitro sob diferentes concentrações de sacarose e crescimento em casa de vegetação. 2000.50 f. Dissertação (Mestrado em Fisiologia Vegetal) - Universidade Federal de Pelotas, Pelotas, 2000.

GRATTAPAGLIA, D.; MACHADO, M. A. Micropropagação. In: TORRES, C.; CALDAS, L. S.; BUSO, J. A. (Ed.). Cultura de tecidos e transformação genética de plantas. Brasília: Embrapa-SPI, 1998. p. $183-260$.

GUERRA, M. P.; DAL VESCO, L. L.; PESCADOR, R.; SCHUELTER, A. R.; NODARI, R. O. Estabelecimento de um protocolo regenerativo para a micropropagação do abacaxizeiro. Pesquisa Agropecuária Brasileira, Brasília, v. 34, n. 9, p. 1557-1563, set. 1999.

KOZAY, T.; KUBOTA, C.; JEONG, B. R. Environmental control for the large-scale production of plants through in vitro techniques. Plant Cell, Tissue and Organ Culture, Dordrecht, v. 51, p. 49-56, 1997.

KRIKORIAN, A. D. Medios de cultivo: generalidades, composición y preparación. In: ROCA, W.M.; MROGINSKI, L. A. (Ed.). Cultivo de tejidos en la agricultura: fundamentos y aplicaciones. Cali: Centro Internacional de Agricultura Tropical, 1991. p. 41-77. 
LEVIN, R.; ALPER, Y.; STAV, R.; WATAD, A. Methods and apparatus for liquid media and semi-automated micropropagation. Acta Horticulturae, Wageningen, v. 447, p. 659-663, 1997.

LORENZO, J. C.; GONZALES, B.; ESCALONA, M.; TEISSON, C.; ESPINOSA, P.; BORROTO, C. G. Sugar cane shoot formation in an improved temporary immersion system. Plant Cell, Tissue and Organ Culture, Dordrecht, v. 54, n. 3, p. 197-200, 1998.

MURASHIGE, T.; SKOOG, F. A revised medium for rapid growth and bioassays with tobacco tissue cultures. Physiologia Plantarum, Copenhagen, v. 15, p. 473-497, 1962.

OSMOTEK LTD. (Rehovot, Israel). Cluster multiplication of potato in liquid medium in lifeline lifereactors (presterilzed, plastic sheet air lift bioreactors): application note 4. Disponível em: <http:// www.osmotek.com>. Acesso em: 5 out. 2000.

SKIRVIN, R. M.; McPHEETER, K. D.; NORTON, M. Sources and frequency of somaclonal variation. HortScience, Alexandria, v. 29, n. 11, p. 1232-1237, 1993.

TORRES, A. C. Cultura de tecido para a obtenção de plantas sadias. In: REIFSCHNEIDER, F. J. B. (Ed.). Produção de batata. Brasília: Embrapa-CNPH, 1987. p. 231-239.

TOVAR, P.; ESTRADA, R.; SCHILDE-RENTSCHLER, L.; DODDS, J. H. Inducción y utilización de tubérculos in vitro de papa. Lima: Centro Internacional de la Papa, 1985. 4 p. (Circular, 13).

ZIV, M. The control of bioreactor environment for plant propagation in liquid culture. Acta Horticulturae, Wageningen, v. 393, p. 25-38, 1995. 